\title{
Identidad y fiscalidad: los gazis de Sevilla ante el pago del Servicio Morisco de 1597
}

\author{
Taxation and Identity: The Sevillian Gazis and the \\ Morisco Tax Payment in 1597
}

\author{
Manuel Francisco Fernández Chaves \\ Universidad de Sevilla, España
}

\begin{abstract}
En este trabajo se analiza la resistencia de grupos de raigambre cultural islámica como los mudéjares y gazis a su inclusión en el «servicio de los naturales del Reino de Granada» creado tras la expulsión de los moriscos de dicho reino a partir de 1591. A través del análisis de diversa documentación, fundamentalmente notarial, se reconstruye la evolución de las categorías de gazi y berberisco desde su presencia en el reino de Granada tras 1502 hasta su ulterior deportación tras la guerra de las Alpujarras. Se estudia aquí la variable interpretación y valoración de estas dos categorías según el interés y posición de los distintos actores implicados en el proceso de homogeneización fiscal que los moriscos impusieron a otras categorías menores de la población neoconversa presente en suelo castellano en el siglo XVI. La resistencia de los mudéjares antiguos y gazis de la ciudad de Sevilla muestra las divergencias que existían tanto en el seno de la comunidad morisca como entre ésta y el resto de gentes de origen islámico en Castilla, que se debían a la diversidad de origen geográfico de su procedencia así como a la colisión de las jerarquías deportadas desde la ciudad de Granada con individuos de otra procedencia y estructuras sociales diferentes.
\end{abstract}

Palabras clave: moriscos; gazis; mudéjares; berberiscos; impuesto; identidad; Reino de Granada.
In this paper the author analyses the resistence of cultural Islamic rooted groups, such as the Mudejares and Gazis, to be included in the "Service of Grenadans", which was created after the expulsion of the Moriscos from the Kingdom of Granada in 1591. Based on studies from different sources, mainly notary records, the paper reconstructs the evolution of the Gazi and Berber categories from their presence in the kingdom of Granada as of 1502 until their deportation after the Alpujarras war. The author researches how the interpretation and assessment of these two categories changes depending on the interest and position of the different parties involved in the fiscal equalization process that the Moriscos imposed onto other minor categories of the new converted population in Castilian land during the XVI century. The reluctance of Sevillian Mudejares and Gazis to pay the new tax shows the differences existing not only within the Morisco community but also between this community and the rest of the Islamic based population in Castile, due to the diverse geographical origin of each group and the conflicts between the deported Grenadan citizen hierarchies with individuals from different origins and social structures.

Key words: Moriscos; Gazis; Berbers; Mudejars, Taxation; Identity; Kingdom of Granada. 


\section{Los gazis en el Reino de Granada}

Se sabe realmente poco sobre los gazis en el Reino de Granada después de la conquista y la conversión general, pues a lo pequeño de su número se añade su eclipse por el interés que han suscitado los moriscos en la historiografía. Según la Nueva Recopilación, la voz gazi se refería a aquellos «que hubieren nascido moros o turcos, en cualquiera parte de Berbería, u otra cosa que sea, ora sean esclavos o libres y rescatados, cristianos o moros» ${ }^{1}$, apareciendo esta definición en la pragmática de 1572 que recogía la recopilación y que se dictó para regular la presencia morisca en el exilio castellano. El verdadero significado de la palabra en árabe es «participante en una cabalgada» ${ }^{2}$ estando formado en origen este contingente por aquellos voluntarios que lucharon en defensa del islam granadino provenientes del Norte de África. Pero para los moriscos y cristianos viejos de finales del siglo XVI el «nombre de gasi es palabra araviga que gasis son todos los cristianos nuevos de moros que sean africanos o turcos o de qualquier nacion de moros e sus desçendientes e que en España no ay otros que se llamen gazes» ${ }^{3}$ o también «los que se llaman gazis en este reino de España son los moros berveriscos o turcos que se bienen a tornar cristianos e sus desçendientes $»^{4}$, añadiendo alguno que eran «los dichos moriscos afri-

Abreviaturas empleadas: AHN, Archivo Histórico Nacional; C, Consejos; D, Diversos; CC, Concejos y Ciudades. AGS, Archivo General de Simancas; CC, Cámara de Castilla; CJH, Consejo y Juntas de Hacienda. AHPSe, Archivo Histórico Provincial de Sevilla; PNS, Protocolos Notariales de Sevilla. AMS, Archivo Municipal de Sevilla.

${ }^{1}$ Gallego Burín y Gámir Sandoval, Los moriscos del Reino de Granada según el sínodo de Guadix de 1554, p. 48, donde citan la Nueva Recopilación.

${ }^{2}$ Según Lewis, Pellat y Schacht, $E I^{2}$, vol. 2, pp. 1043-1044, la voz gazi es un «Arabic active participle used to indicate those who took parte in a razzia [see Ghazw], later in a ghazwa [q.v.] "raid against the infidels". This name later grew to be a title of honour reserved for those who dinstinguished themselves in the ghazwa...». Despuntan como soldados y aventureros protagonistas de cabalgadas en la inestable frontera islamo-bizantina en el siglo XI, y su elemento principal eran turcos. No obstante, ya avisa Javier Castillo que su significado había cambiado en el siglo XVI para designar «a los moros norteafricanos en general, o a sus descendientes, ya fueren libres o esclavos, estuvieran o no bautizados, que residían en la Península", Castillo Fernández, "Las estructuras sociales", p. 211.

3 AHPSe, PNS, leg. 4177, s.f. Interrogatorio del pleito entre los gazis y mudéjares y el repartidor del servicio morisco de Sevilla y su partido Alonso Hernández de Represa, en adelante, Interrogatorio, Testificación del corredor de lonja cristiano viejo Lope de Sancúrjal, s.f., año 1598.

${ }^{4}$ Interrogatorio, Testificación del morisco Hernando de Galves, antiguo vecino de Comares, s.f. 
canos» ${ }^{5}$. Cristianos nuevos de moro, pero diferentes de los moriscos, a fin de cuentas. Considerados por los moriscos como «otros», a finales del siglo XVI éstos tratarían de diferenciarlos también de los berberiscos tratando de asociarlos a ellos en el pago de los nuevos servicios que los moriscos comenzarían a pagar al terminar el Quinientos. Contra este designio, los gazis tratarían de rebelarse a finales del siglo XVI, tratando de asimilarse, como también hicieron algunos moriscos, a los berberiscos, cuya consideración desde el poder político fue siempre más positiva.

Pese a que numéricamente no eran muy importantes, su presencia era lo suficientemente inquietante para que se legislase sobre ellos, siempre en torno a su deseable alejamiento de las costas, pues se les consideraba como peligrosos puntales de amarre cultural y posibles espías del islam magrebí. A las frecuentes huidas allende protagonizadas por los granadinos antes incluso de la conversión de $1501-1502^{6}$, se añadía un efecto contrario: el de la llegada de musulmanes del Norte de África en ocasiones acompañados por moriscos que se afincaban en el revuelto reino y actuaban como bandidos y salteadores. En la correspondencia del conde de Tendilla, «gazi» es sinónimo de salteador y berberisco. En ella, en el año de 1504 y ante los frecuentes desembarcos de berberiscos, el conde de Tendilla escribía a su hombre de confianza encargado de la defensa de la costa del obispado de Granada, el capitán D. Rodrigo Manrique: «Las quadrillas, señor, que fueren tengan ojo a los gazís y moros de allende más que a los [moriscos] que traen armas, que de los vnos pueden matar y tomar y de los otros tomar porque no tyenen pena syno de destierro y perdiçión de bienes? En este aviso, Diego Hurtado de Mendoza distinguía entre los gazis y moros de allende frente a los moriscos, siendo más «rentable» eliminar a los primeros que a los segundos, que tenían mucho más que perder a la hora de encontrarse con los cristianos en las breñas del reino. Los propios moriscos encontraron deseable el prendimiento y/o ejecución

5 Interrogatorio, Testificación del barbero morisco Alonso Ruiz, s.f.

${ }^{6}$ Galán Sánchez, Los mudéjares del Reino de Granada, pp. 47-56.

7 Szmolka Clares, Epistolario del Conde de Tendilla (1504-1506), t. I, p. 79, carta de 16-VI-1504. En otra carta al capitán Hurtado escrita en 3-IX-1504 le indicaba que «todo lo que el señor don Rodrigo mandó en eso de los dos christianos nuevos, está bien hecho, y lo que se proveyó en yr a buscar los gazís está bien», también, p. 129. Sobre los asaltos norteafricanos, véase en la misma obra las pp. C-CII, CXVIII-CXIX. 
de gazis, pues se pagaba por su captura ${ }^{8}$. El problema continuaría por más tiempo, y aún en 1506 se actuaba contra ellos en las Alpujarras", en las que «algunos gazís de allende andan por las syerras salteando», siendo conocidos de algunos vecinos de Granada ${ }^{10}$. La presencia de estos norteafricanos y gazis junto a algunos de los moriscos como bandidos llevaría al rey Fernando a declarar ilegal la posesión de armas de los moriscos en 1511, tratando de regularla en disposiciones subsiguientes ${ }^{11}$. La presencia de norteafricanos como bandidos era muy preocupante, y se añadía a las huidas allende que desestructuraban y vaciaban el territorio. Para evitar que se insuflase nuevo ánimo al islam granadino en 1513 Fernando el Católico ordenó que aquellos que se hiciesen esclavos tras encuentros armados no fuesen vendidos en el reino de Granada, «syno que el que lo tomare se sirva de él lo venda, pero fuera dese Reyno de Granada» ${ }^{12}$. La reina Juana amplió

${ }^{8}$ Así don Íñigo López de Mendoza indicaba en una carta en septiembre de 1514 sobre el prendimiento de «tres moros en la ranbla de Torviscón y syn aver ynformaçion dellos, del que tocava al remedio de la tierra, porque me los querian traer, mató el teniente a dos... El vno, ques gazi, no se sy me lo enbiara... pareçeme a mi que deve morir tanbien, pues ay premática que ningund moro entre en el reyno so pena de muerte, y que ge los deve pagar y luego a los que los tomaron porque con los otros çinco que mataron y con éstos, sy muere, y ge los pagan, son enemistadas aquellas dos tahas para syempre con los salteadores. Tanbien los de Ortega y las Buñelas tomaron otro moro, que llamavan el Corço, que yo yize quartyzar. Escrevi al señor mi hermano que lo mandase pagar, hizose sordo. Esto es lo que mas cunple, procuradlo», Peinado Santaella, Los inicios de la resistencia musulmana en el Reino de Granada (1490-1515), pp. 148-149.

${ }^{9}$ El conde de Tendilla escribía al alcalde mayor de Granada en 9-III-1506 que «teneys presos a los dos vezinos de la taha de Çuhehal de las Alpuxarras porque ayudavan con los gazís de allende salteando, los quales yo vos mandé entregar para que dellos se hiziese justiçia. Agora sabed quel rey, nuestro señor, por una çedula que vereys, me embia mandar que los de y entregue por esclavos a Pedro de Plazençia y a Juan de Morales y Garçía Hernándes y otros sus compañeros, que los tomaron con los otros moros de allende que por mi mandado se les dieron», Szmolka Clares, Epistolario, t. II, pp. 604-605.

${ }^{10}$ Como era el caso del vecino de la ciudad Martín de Luque, que se ofrecía a capturarlos al conde de Tendilla porque «dize... que los conoçe», Szmolka Clares, Epistolario, t. II, p. 733, 4-VII-1506.

${ }_{11}$ Arroyal Espigares, Cruces Blanco y Martín Palma, Cedulario del Reino de Granada (1511-1514), pp. 65-68, Sevilla, 12-V-1511. Sobre la trascendencia de 1511 en el incremento de la presión sobre los moriscos a través de nuevas disposiciones y una más pesada fiscalidad, Galán Sánchez, Una sociedad en transición: los granadinos de mudéjares a moriscos, p. 238-240, sobre el bandidaje y la piratería, pp. 142-145. Ya se dieron prohibiciones de portar armas en algunos lugares como en Murcia en 1488, Granada en 1492, Ronda y Marbella en 1492, a todos los nuevamente convertidos del reino de Granada en 1501, cfr. Ladero Quesada, Los mudéjares de Castilla en tiempos de Isabel I, docs. 19, 52, 57, 141.

12 Arroyal Espigares, Cruces Blanco y Martín Palma, Cedulario del Reino de Granada, pp. 345-346, Segovia, 2-XI-1513. Si bien el destino de muchos «moros» y «gazis» 
esta consideración para aquellos moriscos que huidos allende regresaban como salteadores y al ser capturados eran vendidos como «moros» pues eran prontamente rescatados por sus parientes y conocidos y volvían a incorporarse a las bandas de saqueadores norteafri$\operatorname{canos}^{13}$. Se temía a la solidaridad islámica que llevaba a una rápida liberación de los cautivos, fenómeno que se dio tanto en época mudéjar como en estas primeras décadas del siglo ${ }^{14}$, como tras la guerra de $1568-1570^{15}$. Las cédulas que se emitieron en estas primeras dos décadas del siglo XVI indican la constante preocupación por la actividad de bandidaje impulsada por las llegadas de fustas norteafricanas y la ayuda prestada por muchos nuevamente convertidos ${ }^{16}$, endureciéndose seguramente en 1513 la aplicación de castigos para los moriscos colaboradores, pues en ese año se dan ofrecimientos de moriscos para delatar a los moros de allende ${ }^{17}$. Ese verano se supo de una importante armada de «turcos y moros» en fustas que podía atacar las costas granadinas ${ }^{18}$.

fue el descuartizamiento, previo pago de recompensa, cfr. Moreno Trujillo, Osorio Pérez y Obra Sierra, Escribir y gobernar: el último registro de correspondencia del Conde de Tendilla (1513-1515), p. 372, carta de 12-IX-1514.

13 Arroyal Espigares, Cruces Blanco y Martín Palma, Cedulario del Reino de Granada, pp. 348-350, Segovia, 2-XI-1513. La venta sólo podría efectuarse a cristianos viejos que los fueran a sacar del Reino de Granada. Ya desde el año anterior se estaba revisando la política de perdones a estos moriscos, Arroyal Espigares, Cruces Blanco y Martín Palma, Cedulario del Reino de Granada, p. 221, Burgos, 17-VII-1512.

${ }^{14}$ Galán Sánchez, Los mudéjares del Reino de Granada, pp. 320-322, 330-337.

15 Fernández Chaves y Pérez García, En los márgenes de la ciudad de Dios, pp. 135-136.

${ }^{16}$ Arroyal Espigares, Cruces Blanco y Martín Palma, Cedulario del Reino de Granada, pp. 139-144, 148-150, 212-213, 236-240, etc.

17 En 1513 el rey Fernando perdonaba a moriscos arrepentidos como Diego, de Dalías, que había «andado en conpañía de algunos moros e salteadores que andavan en el dicho Reyno e les distes mantenimientos» y posteriormente los había delatado, cfr. Arroyal Espigares, Cruces Blanco y Martín Palma, Cedulario del Reino de Granada, pp. 254-255. Ese mismo año un morisco de Mojácar llamado Albarreque se concertaba con el capitán Antonio de la Cueva para «entender en çierto trato con los moros de aliende, y dezís que dareys forma como vengan vna o dos o tres fustas de moros a la parte que conçertardes con don Antonio de la Cueva... para que las dichas fustas e moros sean tomados e perdidos», en la misma obra, p. 256. El mismo don Alonso Granada Venegas intercedía por algunos moriscos de Berja que habían colaborado con los piratas para que les perdonasen la sentencia de confiscación de bienes y ejecución, en las pp. 256-257.

18 Arroyal Espigares, Cruces Blanco y Martín Palma, Cedulario del Reino de Granada, pp. 265-267, 269-270. Véase sobre este asunto el estudio de Galán Sánchez, Los mudéjares del Reino de Granada, pp. 27-28, 33-36. 
En la correspondencia del conde de Tendilla se habla de moros y moriscos salteadores, pero en pocas ocasiones se utiliza la palabra gazi ${ }^{19}$, que en algunas ocasiones es ya el apellido o sobrenombre de algunos habitantes del reino, recordándose así su origen ${ }^{20}$. En 1514 el rey Fernando dio una instrucción para reorganizar y reforzar la guarda de la costa y mejorar el control del interior del reino de Granada frente a los gazis, traduciéndose en dos pragmáticas en las que se contemplaba la pena de muerte y confiscación de bienes para los moriscos que los acogiesen y ayudasen, además de no recomendar la imposición del destierro para los cristianos nuevos que hubiesen cometido delitos relacionados con los asaltos, pues al no tener nada que perder los moriscos se unían a los gazis echados al monte ${ }^{21}$.

Entre las disposiciones que se tomaron en la Capilla Real de Granada en 1526 se encuentra la relativa a los Gazies «que aya sido, o sea cautivo, o rescatado» a los que se les prohibía vivir o pasar por las Alpujarras o la costa, debiendo estar a diez leguas de estos espacios, señalándose como pena la caída en esclavitud «porque tenemos informacion que son espias de los Moros, y hazen otros daños», ley que se volvió a confirmar en Madrid en $1528^{22}$. También en 1526 Carlos V se dirigió al Arzobispo de Granada para que los gazis no pudiesen pedir limosna «para su rescate, ni en otra manera, por escusar el dicho trato y conversacion, y la ocassion de andar y tratar en el dicho Reino» ${ }^{23}$, no permitiéndose que estuviesen entre los moriscos «libres

19 Se usa el término por ejemplo en 1513 cuando Mendoza se dirigía al gobernador de Guadix para que le entregase un preso «nuevamente convertido que se dize Tomas; el qual con otros gazis y salteadores que se mataron fue preso», Granada, 21-V-1513, Meneses García, Correspondencia del Conde de Tendilla, t. II, p. 326.

${ }^{20}$ Ejemplos en Moreno Trujillo, Osorio Pérez y Obra Sierra, Escribir y gobernar, pp. 533,738

${ }^{21}$ López de Coca Castañer, "Consideraciones sobre la frontera marítima", p. 405. La evolución de la organización militar del reino y otros asuntos políticos en Jiménez Estrella, Poder ejército y gobierno en el siglo XVI. La capitanía general del Reino de Granada y sus agentes.

${ }_{22}$ Nueva Recopilación de las Leyes de Castilla, Madrid, 1723, libro VIII, título II, ley XIII, f. 293r. A ello se añadía la prohibición para los moriscos de rescatar a moros que no se hubiesen convertido, y una vez hecho debían de «a soldada luego con alguna persona christiano viejo porque lo enseñe a vivir bien», Castillo Fernández, "Las estructuras sociales", p. 211.

${ }^{23}$ Se recoge en Pregmaticas y Provisiones de su Magestad el Rey don Philippe nuestro señor, sobre la lengua y vestidos, y otras cosas que an de hazer los naturales deste Reyno de Granada, s.f. Esta disposición para con los berberiscos había sido ya proclamada en 
ni captibos» ${ }^{24}$. Además se había dispuesto en los capítulos de la congregación de la Capilla Real que «ninguno de los dichos nuevamente convertidos no pudiesse criar niños expositos, ni se sirva de Cristianos viejos menores de veynte años» ${ }^{25}$. En las cortes de Segovia de 1532 Carlos V y su madre Juana dieron una cédula para que los esclavos berberiscos que fuesen rescatados marchasen a vivir 15 leguas al interior de la costa después de un año, previendo diversas penas para los infractores ${ }^{26}, \mathrm{y}$ volvería a repetirse esta disposición en las cortes de Valladolid de 1537. Este temor a su comunicación con el continente vecino se unía a una denuncia hecha a la Emperatriz Isabel anteriormente sobre los «gazis y alarabes hacian algunas zambras en que habia mucha deshonestidad y cosas no bien hechas», castigándose por vía de cédula en 1532 a quienes, esclavos o libres, cantasen los «cantos de Mahoma» y otros, dando sólo licencia para «tañer, cantar y bailar con sus instrumentos músicos en sus bodas y pasatiempos, como lo solían desde que son cristianos $»^{27}$.

No es mucha más la información que tenemos de estos gazis en tierras granadinas desde el punto de vista de la legislación castellana en los años siguientes, y aunque el problema del bandolerismo protagonizado por los monfíes fue importante y las huidas continuaran ${ }^{28}$, los gazis no aparecen asociados a estos bandoleros en la legislación en las décadas posteriores a 1530. No obstante, el problema fue en aumento y la presencia de norteafricanos apoyando a los monfíes continuó en las décadas centrales del siglo ${ }^{29}$. En 1560 Felipe II prohibió en las cor-

1509 en el Reino de Valencia pues muchos eran piratas. Sobre la solidaridad mudéjar y posteriormente morisca para rescatar cautivos de origen islámico, Galán Sánchez, Los mudéjares del Reino de Granada, pp. 332-333.

${ }^{24}$ Mármol Carvajal, Historia del rebelión y castigo de los moriscos granadinos, libro II, capítulo II, p. 133.

${ }^{25}$ Pregmaticas y Provisiones, s.f.

${ }^{26}$ La primera vez cien azotes y la segunda pena de galeras, cfr. Nueva Recopilación, libro VIII, título II, ley VI, f. 292r. Javier Castillo indica que esta orden data de 1531, y fue reiterada en 1537 y 1563 añadiéndose la prohibición de residir en la ciudad de Granada, Castillo Fernández, "Las estructuras sociales", p. 211.

${ }^{27}$ Gallego Burín y Gámir Sandoval, Los moriscos del Reino de Granada, p. 48.

28 Jiménez Estrella, "Los bienes confiscados a moriscos huidos al Norte de África: datos sobre su cobro y administración en el Reino de Granada", vol. I, pp. 517-545.

${ }_{29}$ Así en el Sínodo de Granada de 1565 se indicaba que había moriscos que eran «grandes alteradores monfies que tienen la tierra muy inquieta y peligrosa y que se pasan cada día a Berbería y traen de allí gente de guerra que hazen los robos y captiverios de christianos que Vuestra Magestad sabe», citado en Vincent, "Retour sur les monfíes grenadins”, pp. 31-37, donde se evalúa la importancia de la actividad bandolera morisca. 
tes de Toledo que ningún morisco pudiese servirse de ningún esclavo, no sólo para evitar la enseñanza del islam a los negroafricanos, sino también a evitar la comunicación de esta religión por parte de los berberiscos ${ }^{30}$. En 1566 Felipe II recogería todas estas leyes sobre los gazis prohibiendo específicamente su presencia en el Reino de Granada una vez convertidos al cristianismo, castigándola con las mismas penas y reduciendo el tiempo de su estadía tras la conversión a seis meses ${ }^{31}$. Esta ley se dictaba porque según el rey no se habían observado las disposiciones sobre ellos, e incluso se habían dado licencias por la corona para que vivisen en zonas prohibidas para ellos, incluso dándose licencias para que tuvieran esclavos que se habían «obtenido y avido con falsas relaciones e informaciones, y que an avido la aprobacion de las justicias, y personas a quien esto fue cometido, por medios de favores y negociaciones».

Esta pragmática formaba parte junto a otras cinco que aparecieron publicadas en 1566 de un conjunto de medidas destinado a desarraigar la cultura islámica del Reino de Granada ${ }^{32}$. En su respuesta a estas disposiciones, el mismo Alonso Núñez Muley recordó a los gazis y defendió su coexistencia en el seno de la sociedad cristiano nueva granadina, cuando indicaba que

Echar los gacis deste reino, justa y santa cosa es; que ningún provecho viene de su comunicación a los naturales; mas esto se ha proveído otras veces, y jamás se cumplió. Ejecutarse agora no deja de traer inconviniente, porque la mayor parte dellos son ya naturales, casáronse, naciéronles hijos y nietos, y tiénenlos casados; y estos tales sería cargo de conciencia echarlos de la tierra ${ }^{33}$.

De manera que el vocablo «gazi» designaba a mediados del siglo XVI a un berberisco, pero que en muchos casos había pasado gran parte de su vida en el reino de Granada o había nacido ya en él, aunque se recordaba su origen norteafricano con esta designación.

${ }^{30}$ Martín Casares, La esclavitud en la Granada del siglo XVI, pp. 278-284.

${ }^{31}$ Nueva Recopilación, Libro VIII, título II, ley vii, f. 292r.

32 Pregmaticas y Provisiones, s.f. De todas ellas se hace eco Mármol Carvajal, Historia del rebelión, p. 145, indicando, «que los moriscos no tuviesen esclavos Gacis, aunque tuviesen licencias para poderlos tener».

${ }^{33}$ Mármol Carvajal, Historia del rebelión, p. 159. Esta medida destila un cierto paralelismo con la expulsión parcial de judíos que ya dictasen los Reyes Católicos en Andalucía en 1483, siguiendo la lógica de desarraigar a los que tienen un contacto más reciente con el islam y pueden «contagiar» a los conversos. 


\section{La expulsión del Reino de Granada y el contexto de formación de los nuevos servicios moriscos}

Siguiendo esta lógica de «naturalización» de los gazis y por tanto de relativa igualación a los moriscos pero con un propósito bien distinto al de Núñez Muley, los gazis fueron incorporados a las diversas expulsiones de moriscos que se llevaron a cabo después de la guerra de 15691570. En un primer momento a mudéjares y gazis no se les menciona específicamente en los bandos de expulsión de 1570, y tampoco aparecen en la pragmática más importante que regulaba la gestión de la presencia morisca en Castilla, dada en 1572, en las que sólo se habla de «moriscos». Sin embargo, sí que se les incluye en los bandos de expulsión de los moriscos de 1583, 1584 y $1585^{34}$. Continuaba existiendo pues una condición de «gazi» que se heredaba de padres a hijos y que estaba reconocida en el reino de Granada y en la legislación. No obstante, al repartirse la masa de deportados por el territorio castellano su importancia como elementos desestabilizadores en relación con el Norte de África prácticamente desaparece.

¿Por qué se da entonces la supervivencia de la condición de «gazi»? Además de la obvia respuesta que se obtiene al considerar la constante entrada de berberiscos como esclavos en Andalucía, se dio también por su parte una consciente diferenciación frente a los moriscos, pues su categoría social era diferente de éstos y obtendrían, en teoría, un tratamiento diverso. Pero también es probable que entre los moriscos no cundiera un especial aprecio por estos recién llegados, afines cultural y espiritualmente, pero no iguales. El hecho de que sobreviviera el mismo término árabe que les designa implica una raigambre de su consideración anterior a la conquista del reino nazarí. Además es probable

\footnotetext{
${ }^{34}$ Una provisión de 26-I-1584 dirigida por Felipe II al concejo de Antequera remitía ya a una cédula de 28 -XI-1583 por la que se ordenaba que «todos los moriscos mudexares y gacis honbres y mugeres y niños de qualquier edad que fueren que uviese en este reino ansi los que quedaron en administracion como en otra cualquier manera se recogiesen y alistasen y sacasen de el en virtud de la qual se enviaron hordenes a los corregidores deste dicho reino». En otra de 2-III-1585 el rey indicaba a sus corregidores «que por cedulas nuestras y horden de los del nuestro consejo que reside en la ciudad de Granada tenemos mandado que los moriscos mudejares y gazis que avian quedado en el nuestro reino de Granada y en esa dicha ciudad saliesen de la tierra adentro como se hizo al tiempo que los demas se reduxeron a nuestra obediencia», Archivo Histórico Municipal de Antequera, Fondo Municipal, leg. 3992, carpeta 1, doc. 1, carpeta 5, doc. 1. Sobre la presencia morisca en Antequera, Pérez García, "Moriscos en Antequera, 1569-1574".
} 
que los gazis se especializaran en cierto tipo de trabajos y con ello se hiciesen necesarios en algunos sectores económicos, ocupando antes de la guerra diversas profesiones relacionadas con los servicios y trabajos de poco nivel ${ }^{35}$.

Así por ejemplo, en 1584 la ciudad de Alcalá la Real no quería dejar salir a «sus» moriscos allí llegados tras las ultimas sacas del reino de Granada haciendo frente a la Chancillería granadina y al corregidor «por no pertenecer a este reino y por la necesidad que hay de los gaçis para el trasiego del vino» ${ }^{36}$. Esta especialización no era extraña a colectivos marginales, y la encontramos también para los berberiscos. Así algunos de los trabajadores de origen berberisco en Sevilla se habían especializado como estibadores en el puerto (trabajadores de la palanca). Otro tanto podía decirse de los berberiscos en Málaga, donde muchos de ellos desde los primeros años del siglo XVI fueron empleados como mano de obra en el campo y como estibadores en el puerto, fabricantes de aparejos, etc., trabajando en «cosas bajas de ganapanes que es de lo que sirven los dichos esclavos» ${ }^{37}$, siendo su papel económico muy importante, pues según un contemporáneo, «quitar en Málaga el servicio de los esclavos es quitar en Castilla la Vieja el servicio de la gente libre» ${ }^{38}$. Más al interior su trabajo era también muy necesario, y así después de la expulsión de los moriscos el problema berberisco continuó creciendo. En la ciudad de Antequera el rey recordaba en 1614 a los propietarios de esclavos berberiscos «que se alquilan a xornal para tratar de sus rescates e sustentar sus amos» que aquellos tenían

sus cassas y familias de por si y no con subjecion ni administraçion de ningunas personas cristianas que los administren dotrinen ni enseñen ni sus amos ynquieren ni saven que modo de bibir tienen se hazen ya an hecho muchas ofenssas a dios y a co-

35 Castillo Fernández, "Las estructuras sociales", p. 212.

36 Juan Lovera, "Apuntes sobre Alcalá la Real en época de los Austrias", p. 972. Como gazi se avecindaba en aquella localidad Juan Izquierdo, frente a otros seis deportados que se identificaban como moriscos.

${ }^{37}$ López de Coca Castañer, "Esclavos, alfaqueques y mercaderes en la frontera del mar de Alborán (1490-1516)", p. 282. Son protagonistas destacados en los autos de la Inquisición desde el siglo XVI, véase, Pérez de Colosía Rodríguez, "Esclavos berberiscos sentenciados en el Auto de Fe de 1618", pp. 357-365.

38 Vincent, "Les esclaves à Malaga en 1581", p. 431. Los esclavos de procedencia norteafricana o turca representaban más del $90 \%$ del total en los siglos XVI y XVII según Gómez García y Martín Vergara, La esclavitud en Málaga entre los siglos XVI y XVII, pp. 28-29, 48-49. 
metido y cometen munchos delitos y es caussa teniendo los dichos moros la dicha libertad y sus cassas aparte que los cristianos viejos ymitan o pueden ymitar sus malas costumbres o modo de bibir demas de que en las dichas cassas los dichos moros y moras receptan encubren y ocultan munchos hurtos y a personas de mal bibir.

Por todo ello se ordenaba residir los esclavos berberiscos en casa de sus amos. Los propietarios de esclavos se defendían argumentando que llevaban empleándolos desde hacía cincuenta años y que no había nadie que sirviera «por tan poco preçio como los moros lo hazen, demas que en todas las ciudades destos reynos se usa y esta permitido andar al jornal por el beneficio de la republica» ${ }^{39}$.

En toda esta polémica, en la que sobresale el valor de estos norteafricanos como trabajadores baratos y esforzados, es de destacar que la palabra «gazi» ha sido desplazada por la más común de «berberisco» o «moro», puesto que los «gazis» constituían una minoría establecida en el reino de Granada cuyo origen se asociaba a los antiguos combatientes por la fe llegados a aquel reino, mientras que muchos berberiscos llegaban como esclavos a la península. Pero la mejor consideración de éstos, asociada siempre a una conversión al cristianismo y a una falta de raigambre en tierras peninsulares haría atractiva la asimilación a berberiscos desarraigados para moriscos y gazis. ¿Respondía entonces el uso de la categoría «gazi» a una consciente explotación de sus posibilidades jurídicas por algunos moriscos que quisieron evitar que no contribuyesen en los nuevos servicios que se crearían a finales del siglo XVI?

\section{Los mudéjares antiguos, gazis y berberiscos en Sevilla y la queja contra los moriscos}

La presencia de los gazis entre los moriscos de Sevilla ha sido mal detectada por la historiografía por las razones anteriormente aludidas

\footnotetext{
39 Otro daño que añadían era el de la falta de correspondencia de los musulmanes norteafricanos a la hora de rescatar a los cautivos cristianos si a sus correligionarios esclavizados en la Península se les impedía la posibilidad del rescate, a lo que se añadía el perjuicio causado a la marquesa del Castellar que como poseedora del oficio de Alfaqueque mayor perdería los diez ducados «de cada cabeça de los moros que rescatados pasan a Berberia». Finalmente parece que la orden real se cumplió, si bien ignoramos si tuvo un efecto duradero. AHN, D, CC, leg. 25, exp. 24, 12-II-1614.
} 
en el caso del reino de Granada. Su suerte corrió pareja en casi todo a la de los moriscos y continuó por este derrotero al ser incluidos en los esfuerzos que los moriscos realizasen desde finales de los años setenta para conseguir reactivar su fidelidad a la corona a través de un servicio pecuniario, hecho que sólo se produciría después de 1588 con un primer servicio que comenzaría a pagarse en 1592 y sería renovado en 1596 y 1603, como recientemente se ha venido señalando ${ }^{40}$. En este sentido, los moriscos de la ciudad de Sevilla jugarían un papel destacado, dándose pugnas entre distintas facciones por el dominio de la fiscalidad diferencial como crucial elemento de control de la minoría al tiempo que de interlocución con las autoridades cristianoviejas ${ }^{41}$. En todo este proceso destacó como comisionado de Felipe II y más tarde Felipe III para la cobranza del repartimiento del servicio de los naturales del Reino de Granada en Sevilla y su partido el morisco Alonso Hernández de Represa, poderoso mercader hecho a sí mismo en el que depositaron su confianza las élites moriscas de la ciudad y que hubo de enfrentarse a algunas tensiones con algunos sectores de estas élites ${ }^{42}$ y con otros neoconversos poco convencidos de la necesidad de pagar un impuesto extra ${ }^{43}$. Entre ellos se contaron también algunos gazis que trataron de potenciar su condición diferencial frente a los moriscos y escapar así al pago del nuevo impuesto.

En la mayor parte de la documentación de la ciudad no se alude nunca a gazis, sino a berberiscos. Al igual que en la zona de Málaga, los berberiscos también fueron importantes como mano de obra en la ciudad de Sevilla, y en el pleito que se abrió entre ellos y los moriscos éstos no dudaban en indicar que aquellos trabajaban en calidad de «palanquines, panaderos e tenderos e travajadores en el Alhondiga de alhameles e de oficios bajos» y en «travajos en la plaça e rio... de esta

${ }^{40}$ Cfr. Bravo Caro, "Un impuesto de desterrados. El servicio de los naturales del Reino de Granada", pp. 45-82; Moreno Díaz del Campo, “Aproximación al estudio de las fuentes para el estudio de la fiscalidad morisca: el ejemplo de La Mancha", pp. 1-16 y Moreno Díaz del Campo, "El último servicio morisco".

${ }^{41}$ Cfr. Pérez García y Fernández Chaves, "La gestión de la fiscalidad como medio de ascenso social en el seno de la comunidad morisca granadina, 1502-1610"; Pérez García y Fernández Chaves, "Los hermanos Berrio: capital morisco, mediación política y transformaciones comunitarias". Por último, nuestro libro de próxima aparición, Pérez García y Fernández Chaves, Las élites moriscas entre Granada y el Reino de Sevilla. Rebelión, castigo y supervivencias.

${ }_{42}$ Pérez García y Fernández Chaves, "Los hermanos Berrio".

43 Pérez García y Fernández Chaves, "La gestión de la fiscalidad". 
çiudad» $»^{44}$. Sin embargo, por motivos que desconocemos entre 1595 y 1597 se había prohibido su actividad laboral en la Alhóndiga ${ }^{45}$. Esto debió de causarles no pocos quebrantos económicos, expresados por su representante, el berberisco Juan Vicente, quien solicitaba al cabildo la readmisión del colectivo en la alhóndiga, hablando

por mi y en nombre de los demas berberiscos que residimos y bivimos en esta ciudad de Sevilla digo que por mandado de vuestra señoria yo y mis consortes estamos desterrados de la Alhondiga del pan desta ciudad siendo basallos del rey nuestro señor y munchos de nosotros no tenemos culpa ni avemos cometido delito porque se nos quite que no entremos en el Alhondiga porque lo que unos hazen no es justo que lo paguen otros. Pido y suplico a vuestra señoria nos mande alçar el dicho destierro dando fianças cada uno de por si por la horden que vuestra señoria mandare y vuestra señoria puede mandar que el que delinquiere lo castiguen corporalmente porque condenandolo en dineros tornan a hazer otros nuevos delitos y en ello vuestra señoria provea lo que mas fuere servido de manera que los que no tenemos culpa no recibamos agravio porque no tenemos en que trabajar y morimos de hambre nosotros y nuestras mugeres e hijos ${ }^{46}$.

Los berberiscos aumentan su importancia como grupo en los años finales del siglo, quizás porque su número era mayor que en tiempos pasados, o porque habían participado de la relativa prosperidad que algunos moriscos habían alcanzado tras su azaroso asentamiento caste1lano. Desde luego existía un buen número de berberiscos en la ciudad habida cuenta de su condición de centro esclavista de primer orden así como por las necesidades económicas que de mano de obra se daban tanto en la propia urbe como en su espacio agrícola circundante ${ }^{47}$. Una

${ }^{44}$ Interrogatorio, Testificación de Alonso Enríquez, cobrador de la renta de la alcabala del carbón, vecino en Omnium Sanctorum, s.f.

${ }_{45}$ Es posible que esto estuviera relacionado con el asalto anglo-holandés a Cádiz de 1596 que puso en estado de alarma a la ciudad. En este sentido ha de recordarse que el principal de depósito de armas de la urbe se encontraba en la Alhóndiga municipal.

${ }_{46}$ AMS, Escribanías de Cabildo del siglo XVI, tomo 4, doc. 45. Este berberisco que firma con bastante destreza, aparece arrendando unas casas en 1604 por 24 reales al mes y 4 gallinas al año, sitas en la calle de la Garbancera en San Lorenzo, AHPSe, PNS, leg. 236, f. 1074r-1075v.

47 Aunque la proporción de esclavos berberiscos y blancos es muy pequeña en comparación con los esclavos negros y moriscos vendidos en la ciudad en el bienio de 15691570, su presencia sería constante en los dos primeros siglos de la modernidad, Cfr. la muestra analizada para estos dos años en Fernández Chaves y Pérez García, En los márgenes de la ciudad de Dios, pp. 86-87, passim. Su importancia no decaerá hasta mediada la decimoséptima centuria, como demuestra Santos Cabota, "El mercado de esclavos berberiscos en la Sevilla del siglo XVII", vol. 1, pp. 599-615. 
denuncia anónima de 1581 aseguraba que en la ciudad de Sevilla había una gran cantidad de berberiscos que practicaban su religión y la inculcaban a sus hijos ${ }^{48}$.

Lo cierto es que los testimonios de la presencia de berberiscos son muy abundantes. Amén de estar organizados laboralmente como es en el caso de la alhóndiga, y haber elegido un representante para aquella ocasión, se daba la presencia temporal de norteafricanos que estaban en Sevilla seguramente por negocios, como los dos matrimonios que en 1598 regresaban a África gracias a un préstamo del portugués residente en Ceuta Luis Pinto ${ }^{49}$. En algunos casos no fueron sólo esclavos los presentes en la ciudad, sino que también se encontraron miembros de las élites del islam mediterráneo. Así entre otros casos que se dieron en el siglo XVI, en el año 1580 se leía en el cabildo la petición de «Çayn» alcaide de Fez, en la que solicitaba limosna dado que había llegado a Sevilla para tornarse cristiano ${ }^{50}$. También por aquellos años los capitulares recibieron un pequeño memorial de Averino de Negroponte que junto a su mujer y sus tres hijas «turcos de naçion gente noble y principal cavallero el qual tenia diez lugares suyos que el gran turco le avia dado y en su casa y serviçio treynta y seis cauptivos cristianos y quarenta cavallos suyos en su cavalleriça» se hallaban en Sevilla después de haber salido del Imperio Otomano y haber sido bautizados en Roma, «enspirados por dios nuestro señor y dexaron toda la susodicha hazienda solo por venir a la fe de cristo nuestro señor». Pedían limosnas para sacar al resto de su familia del imperio, para lo que se valían de un breve concedido por el papa, debiendo ya 400 reales prestados por particulares en la ciudad ${ }^{51}$.

Estas élites reforzaban con su presencia la diferenciación de los berberiscos frente a los moriscos y mudéjares, borrando aquellos (en algunos casos) su pasado islámico echando mano del recurso de solicitar

48 AHN, C, leg. 53305, denuncia de 9-V-1581.

49 Eran Maluq y Almira, Alí y Fátima, «todos quatro moros de naçion estantes al presente en esta çiudad de Sevilla libres» a los que Luis Pinto había prestado 102 ducados para ir a «Berberia que es nuestra tierra». AHPSe, PNS, leg. 207, f. 800r. 4-IX-1598. n. 160 .

${ }^{50}$ Fernández Chaves y Pérez García, En los márgenes de la ciudad de Dios, p. 268,

${ }^{51}$ AMS, Papeles Importantes, t. 9, f. 90. Memorial sin fechar. Sobre la presencia de élites políticas musulmanas en la península cfr. Alonso Acero, Sultanes de Berbería en tierras de cristiandad. Exilio musulmán, conversión y asimilación en la Monarquía Hispánica, siglos XVI y XVII. 
una ejecutoria de cristiano viejo, entrando en competencia con los moriscos por esta cuestión ${ }^{52}$.

En este contexto los moriscos van a incluir a los gazis junto a los mudéjares antiguos en el pago de los nuevos servicios ofrecidos a Felipe II, si bien su consideración jurídica y política había sido oscilante. Así sucedió desde el primer servicio de 1591, pactado según el rey por «las personas que aqui [la corte] vinieron en nombre de los demas naturales de Granada». La cédula que lo organizaba ordenaba al asistente de Sevilla que

\begin{abstract}
dexeis e consintais a los dichos naturales de Granada juntarse a hazer el dicho nombramiento de personas para que hagan el dicho repartimiento por menor los dias y oras y en las partes e lugares que quisieren y señalaren para ello en el qual an de contribuir todos los naturales del dicho Reyno de Granada y mudejares y gaçis que ayan vivido y viven en el dicho Reyno de Granada y a el presente estan en el y fuera del donde quiera que estuvieren e se hallaren en todos estos mis Reynos e señorios asi los alistados como los que no lo estan no enbargante qualesquier previlegios, proviçiones y cartas executorias que tengan que por ser para necesidades $\tan$ presisas e defençion e aumento de nuestra sancta fe catolica ${ }^{53}$.
\end{abstract}

Si antes de la guerra en el reino de Granada no se hacía distinción entre los moriscos como sujetos fiscales a los grupos constituidos por mudéjares antiguos (de Castilla) ${ }^{54}$ y gazis, tras las deportaciones del reino de Granada en los nuevos servicios que pagaron los moriscos en Castilla se especificaba que ambos grupos se añadían a los moriscos y no podían eximirse del pago $^{55}$. Por ello a comienzos del siglo XVII

52 Es el caso del berberisco Álvaro de Torres, que probaba en 1589 ser hijo de Francisco de Torres Alquimima y por tanto se le otorgaba una ejecutoria de cristiano viejo, AGS, CC, libro de cédulas 263, f 52v, Madrid, 13-I-1589. Anteriormente, en 14-XII-1585 el berberisco Benito de Padrela había sido reconocido como hijo del berberisco Sebastián de Padilla y por tanto reconocido como cristiano viejo, ibid, f. 32v.

53 AHPSe, PNS, leg. 4145, f. 130v-131r, El Pardo, 12-XI-1591.

${ }^{54}$ Salvo en la época mudéjar, cuando éstos pagaban desde 1495 dos castellanos de oro como «en Castilla» y tenían sus interlocutores mudéjares junto a los moriscos, Galán Sánchez, "El dinero del rey y la «ley de la comunidad». Pacto político y contrato fiscal en el Reino de Granada tras la conquista", pp. 661-664. Sobre la evolución de la fiscalidad mudéjar, Galán Sánchez, "El precio de la fe en la Castilla Bajomedieval: La fiscalidad de los mudéjares", pp. 187-212.

55 A Jerónimo Rodríguez, uno de los repartidores del servicio de Pastrana que en 1606 quiso evitar dicha responsabilidad además de no abonar su parte se le respondió que por «el capítulo séptimo de dicho asiento está dispuesto que contribuyan en el dicho serviçio todos los naturales del dicho Reyno de Granada, mudexares y gazis, exemptos y no exemptos, sin embargo de qualesquier çedulas, executorias, requisitorias y otros qualesquier re- 
aquellos que pretendían ser cristianos viejos añadían no descender de gazis $^{56}$. Pero si leemos con atención la cédula de Felipe II de 1591 se indica que quienes han de pagar son mudéjares y gazis que hubiesen vivido en el Reino de Granada, no los mudéjares de otras procedencias ni los berberiscos. Por ello los gazis tratarían de zafarse del pago de los servicios moriscos haciendo hincapié en su origen norteafricano tratando de soslayar su larga habitación en el reino de Granada.

La misma corona fue modificando su punto de vista y haciendo distinciones entre los moriscos que ahondaban en la posterior diferenciación fiscal. Dichas distinciones se basaban en el grado de culpabilidad de unos y otros. Se distinguió entre moriscos «de paces» y «rebelados» $\mathrm{y}$ esto fue generando una diversa consideración ante el poder que se añadía a otras categorías ya ensayadas en el reino de Granada como la de bautizado antes de la conversión general, o la de un supuesto origen cristiano viejo, entre otras. De esta manera, en mayo de 1584 (coincidiendo con la última saca de moriscos del reino de Granada, ese año y el siguiente), la corona decidía premiar a los moriscos de paz y colaboradores repartidos en Castilla reconociendo a través del Consejo Real su diferencia y la necesidad de recibir un mejor trato frente a sus correligionarios rebelados, reconociéndose la labor productiva de los moriscos y su aporte a la agricultura, indicando la cédula real, «lo que mas sentiades era la infamia general que de vuestras personas se tenia, teniendoos a todos por malos y de la misma condición e igualdad que los de vuestra nación lo habían sido haziendo robos y salteamientos, lo qual no se había de resumir de bosotros $\rangle^{57}$.

En el seno de todas estas diferencias que revelan una gran complejidad en el conjunto de los moriscos y de otros súbditos del rey católico de origen islámico surgió a finales del año 1598 un intento de diferenciación efectiva que partía de uno de estos grupos, concretamente de los gazis liderados por dos de ellos, Andrés de Barrientos y Pedro de

caudos que tengan, aunque en ellos se mande que no paguen ni contribuyan en el dicho serviçio», cfr. Moreno Díaz del Campo, "El último servicio morisco".

${ }_{56}$ Así en la probanza de Juan López de Rebollar, vecino de Antequera éste indicaba que «mis abuelos fueron cristianos viejos de limpia y clara generaçion y por tales avidos e tenidos sin ser decendientes de moros, mudexares y gaçis ni judios, ni penitenciados ni castigados por el Santo Oficio», AHN, D, CC, leg. 34, probanza de 30-IX-1603, s.f. Esta probanza es citada también por Bravo Caro, "Un impuesto de desterrados", pp. 55-56.

${ }^{57}$ García López, "Conflictividad y conciencia. La aplicación de justicia y la minoría morisca en el reino de Castilla", pp. 460-461. 
Molina, quienes pleitearían ante la Audiencia de Sevilla para evitar su inclusión en los repartos hechos por el morisco Alonso Hernández de Represa y el resto de los representantes de la comunidad. A ellos se unieron los mudéjares presentes en la ciudad, pues el índice del legajo en el que se recogieron las escrituras notariales de aquel oficio y año reza, «Los naturales del reyno de Granada con los modexares e los gazis», aunque nada sabemos de su papel en este pleito, más allá de que no querían participar en el servicio morisco ${ }^{58}$. De este pleito sólo se ha conservado el interrogatorio correspondiente a los testigos presentados por Represa, por lo que no conocemos ni las deposiciones de los gazis ni las de los mudéjares, ni tampoco su desenlace, si bien sabemos que ambos grupos continuaron siendo incluidos en el pago del servicio, pues son mencionados de nuevo en las cédulas de reparto de $1603^{59}$, que comienzan aludiendo sólo a los «naturales del Reyno de Granada» pero a los que se añaden posteriormente «Mudejares y Gazis, exemptos y no exemptos» ${ }^{60}$.

Desde el punto de vista de los testigos que hablan a favor del demandado (Hernández de Represa), todos moriscos excepto dos, los gazis se nos presentan bajo una luz grisácea (de los mudéjares no se dice nada). Todos coinciden en señalar lo bajo de sus actividades laborales, a lo que se añadía que «ninguno dellos sirve ni a servido a su Magestad con armas ni caballos ni es jente para esto e que aunque este testigo a estado en el dicho reino de Granada e a visto en ella jente de guarniçion y en otras partes.... $\rangle^{61}$. El razonamiento consistía en que difícilmente gentes de tan baja condición podrían servir al rey como soldados. Para aquel momento los moriscos habían sido ya movilizados en varias ocasiones

${ }^{58}$ Las resistencias en el seno de la comunidad neoconversa al pago del servicio fueron muchas, tanto en Sevilla (Pérez García y Fernández Chaves, "La gestión de la fiscalidad"), como en la Granada morisca, Galán Sánchez y Peinado Santaella, "La communauté et le roi: Formes de recouvrement et résistances fiscales à Grenade après la conquête", pp. 441-450.

${ }_{59}$ En 1603 volvía a mencionárseles expresamente y en las cédulas enviadas a cada comisario se indicaba que «los Naturales del Reyno de Granada, Mudejares y gaçes que residen en estos mis Reynos teniendo consideracion a las muchas cossas del Servicio de Dios nuestro señor y mio... queriendome ayudar...», AHN, D, CC, leg. 34, s.f.

${ }^{60} \mathrm{AGS}, \mathrm{CJH}$, leg. 434, cédula de 4-I-1603 en la que se añaden a los 240.000 ducados del servicio 10.000 ducados para el Duque de Lerma. Sobre este sobrecosto en el servicio, Moreno Díaz del Campo, "El último servicio morisco".

${ }^{61}$ Interrogatorio, Testificación del corredor de lonja cristianoviejo Lope de Sancúrjal, s.f. 
como zapadores y auxiliares del ejército ${ }^{62}$, lo que significaba que desde su punto de vista eran aún menos fiables que los naturales del reino de Granada. Esto se debía también según los testigos a que la mayoría de ellos estaban herrados en el rostro y por tanto era más que evidente su pasado esclavo, pues en palabras del morisco Hernando de Mendoza

que todos los gazes y cristianos nuevos de moros estan herrados en las caras por donde claramente se entiende que no vinieron a España de su voluntad sino que los trujeron cautivos a ella e algunos dellos conocio este testigo en la ciudad de Granada e sabe que son de los que vinieron a socorrer e ayudar a los revelados del dicho reino ${ }^{63}$.

Su participación en la rebelión es suscrita por otros testimonios en los que se recuerda que además

muchos de los dichos gazes que se avian benido de Berberia huyendo por delitos que avian hecho alli e se juntaron con los que aca andavan en el dicho revelion y fueron munchos dellos cautivos... y quando se echo bando que se biniesen de pas se vinieron muchos dellos con los naturales del dicho reyno e munchos dellos se pasaron a Berberia con los dichos naturales del dicho reino de Granada que se pasaron alla e que los que se quedaron entiende este testigo que fue por no poder passar alla por los delitos que alla avian fecho e que... los dichos gazis que estavan juntados con ellos en el rebelion les dezian que se podian bien fiar de ellos porque venian huyendo de sus tierras por delitos ${ }^{64}$.

Este testimonio recoge ampliado otros tantos en los que se presenta a los gazis como proscritos del islam norteafricano, participantes en la rebelión del reino de Granada y por tanto no exentos de culpa y menos aún de castigo, incluyendo el servicio fiscal, en la lógica que ya hemos visto.

A nivel tributario, los gazis son vistos como una parte integrante de los moriscos, y éstos los incluyen junto a los mudéjares y el resto de moriscos en los servicios que se pagaban en el reino de Granada. Así contestaban los testigos de Represa a la octava pregunta del interrogatorio, recordando que

los naturales del reino de Granada los gasis que son berberiscos convertidos y rescatados y los mudejares todos pagaban la farda y los otros serviçios que se les repartian en la dicha ciudad de Granada syn aber diferenzia entre los unos ni los

${ }^{62}$ Vincent, "Los moriscos granadinos y la monarquía (1570-1609)", pp. 174-176.

${ }^{63}$ Interrogatorio, Testificación del especiero morisco Hernando de Mendoza, s.f.

${ }^{64}$ Interrogatorio, Testificación del corredor de lonja cristianoviejo Lope de Sancúrjal, s.f.

Al-Qanțara XXXVI 1, 2015, pp. 107-139 ISSN 0211-3589 doi: 10.3989/alqantara.2015.004 
otros sobre la dichas pagas porque todos contribuyan y pagaban igualmente syn distincion alguna ${ }^{65}$.

$\mathrm{Y}$ en efecto, en las distintas órdenes para repartir la farda no se hace distinción de unos ni de otros y se habla sólo de «nuevamente convertidos $»^{66}$, pero esta fórmula no parece incluir a los mudéjares antiguos, que aparecen señalados específicamente cuando se trata de hacer extensivos a ellos prohibiciones como la del vestido a la morisca o el portar armas ${ }^{67}$; de los gazis, nada se contempla en estas disposiciones. Un testigo del interrogatorio recordaba cómo había visto prender

en Padul a un gaze que llamavan el Meliche que dijo que era natural de Melilla descendiente de naturales aunque dezia que hera previlejiado e que podia estar en el dicho reino lo llevaron preso a la carcel de Granada e que siempre a visto que todos los bandos que se han echado contra los granadinos conprendian a los gazes y siempre se dezia en ellos moriscos y gazes ${ }^{68}$.

Algunos testigos señalaron que los gazis habían participado como los demás moriscos en la votación para repartir el nuevo servicio. Uno de ellos era el especiero morisco Hernando de Mendoza quien recordaba

que en la junta que se hizo en el año pasado de noventa e siete para nombrar repartidores e otros oficiales para la cobranza del dicho servizio por mandado del dicho Alonso Hernandez comissario, que se hizo en una cassa que solia ser hospital que esta junto a la Compañia de Jesus desa ciudad vido este testigo se juntaron con los dichos naturales del dicho reino de Granada otros tres o quatro gazes que no se acueda de sus nombres e tambien se junto el dicho Andres de Barrientos e que se remite a las listas que entonzes se hizieron de los que alli se juntaron ${ }^{69}$.

${ }^{65}$ Interrogatorio, Testificación del barbero morisco Alonso Ruyz, s.f.

${ }^{66}$ Por ejemplo en 1513, cfr. Arroyal Espigares, Cruces Blanco y Martín Palma, Cedulario del Reino de Granada, pp. 273-276.

${ }^{67}$ Los cristianos viejos y mudéjares confeccionaban ropa morisca pese a las prohibiciones porque argüían que éstas estaban dictadas sólo contra los «nuevamente convertidos»; también en 1513 se incluía a los mudéjares en la prohibición de portar armas, Arroyal Espigares, Cruces Blanco y Martín Palma, Cedulario del Reino de Granada, pp. 292, 299. Asimismo, en 1512 se daba una orden para espiar a los «mudéjares y granadíes» para averiguar si tenían armas y confiscárselas, Cedulario, p. 214.

${ }^{68}$ Interrogatorio, Testificación del corredor de lonja cristianoviejo Lope de Sancúrjal, s.f.

${ }^{69}$ Interrogatorio, Testificación del morisco Hernando de Mendoza, especiero vecino de San Isidro, s.f. 
Esto debía de ser cierto, si bien en la documentación que hemos encontrado tanto de las reuniones para organizar el servicio como en un poder general que dan los moriscos de Sevilla para que Alonso Hernández de Represa les representase, sólo aparecen «naturales del dicho rreyno de Granada vezinos de la dicha ciudad y su tierra y partido» ${ }^{70}$, sin ninguna mención a gazis o mudéjares, lo que nos indica que estos colectivos debieron de estar marginados de la toma de decisiones trascendentes para los neoconversos. Sin embargo Represa actuaría en nombre de «naturales del dicho Reyno de Granada mudexares y gazes desta dicha ciudad y su tierra y partido», que es como rezaba la cédula de repartimiento del servicio.

A través del interrogatorio se señala cómo la actitud de los gazis no era otra que la deserción, la deslealtad para con la corona y con sus correligionarios, bajo la que se escondía no sólo una vileza de su origen, como proscritos y rebelados, confirmada en sus actividades laborales, sino también un elaborado proceso de fraude fiscal de muchos moriscos, que son acusados por sus correligionarios. En efecto, según varios testimonios,

algunos de los dichos gassis son hijos de los moriscos del dicho reino de Granada que se pasaron a Berberia y que este testigo conose en esta ciudad un natural del dicho reyno de Granada que aunque se save el nombre no lo dize que siendo natural del rio de Almeria se haze gasi berberisco y se defiende diziendo que no a de pagar el dicho servicio o mesmo otro buñolero que vibe en los Humeros los quales tienen hecho provanza de gassi siendo naturales del dicho reyno de Granada ${ }^{71}$.

Como hemos visto este fenómeno data de los primeros años de la Granada morisca, que la reina Juana trató de sancionar en una cédula de $1513^{72}$. Para algunos este hecho ya había comenzado en la propia ciudad de Granada, donde «algunos de los dichos gasis que se nombravan africanos eran hijos de andaluzes y nacidos en el dicho Reyno

70 Pérez García y Fernández Chaves, Las élites moriscas.

${ }^{71}$ Interrogatorio, Testificación del morisco buñolero Alonso de Herrera, s.f.

${ }^{72}$ La reina indicaba que «no se puede enteramente saber la verdad sy son moros o nuevamente convertydos, y los más de ellos se venden por moros y los compran los nuevamente convertidos del dicho Reyno, e luego andan sueltos por la tierra, y sy son de los nuevamente convertidos y ven que no se pueden encobrir, sy le conpra cristiano viejo, porque los venden por moros, tienen forma como los tornen cristianos diziendo que son de allende», Arroyal Espigares, Cruces Blanco y Martín Palma, Cedulario del Reino de Granada, p. 349. 
de Granada y ellos gustaban de que les llamasen gasis siendo hijos de andaluzes por gozar de las premynencias de traer armas y otras de que gozan los dichos gasis» ${ }^{73}$ entre las que se contaba una mayor libertad de movimientos. Esto lo corroboraba el cristiano viejo Lope de Sancúrjal, que afirmaba que

con las bentas que hazian dellos [moriscos esclavos] y en las cartas de libertad les llamavan moriscos ververiscos y sus amos les ayudaban a ello porque les estava bien que los dichos sus esclavos los pudiesen acompañar con armas e por otras causas e que esto lo save este testigo porque lo a visto como persona que vivio en la dicha ciudad de Granada ... y lo ha visto en esta ciudad como corredor de lonja ${ }^{74}$.

Todos los testigos de la probanza corroboraban esta y otras afirmaciones similares remitiéndose a las cartas de libertad, pues de hecho en las mismas se recogía la dudosa condición de los moriscos/berberiscos. De esta manera en 1587 Don Pedro Marmolejo reconocía que su madre, D a . Beatriz Barba había ahorrado a Hernán García «morisco de Berbería», el pasado año de 1581, declarando ahora que

como quiera que en la dicha carta de alhorría que la dicha mi madre os hizo dize que soys morisco de los del reyno de Granada, a mi [me] consta que soys berberisco y ansí lo teneis provado y aberiguado ante el liçençiado Yñigo de Leçiñana, provisor de Sevilla, y ante el conde de Orgaz, don Juan Jurtado de Mendoça, Asistente de Sevilla, y por autos proveidos por los suso dichos, atento a la dicha ynformación que distis os an dado y dieron por morisco berberisco, y si algún derecho y açión contra vuestra persona e vuestros bienes tengo y me perteneçe e puede pertenecer yo me dexo y desisto dello... y agora al presente teneys quitados los hierros que teniades en el rostro al tiempo y quando la dicha mi madre os hizo el dicho ahorramietno y demás desto teneis el colmillo del lado yzquierdo de la enzía alta quebrado por medio... ${ }^{75}$.

Este mismo «morisco berberisco» había dado un poder el año anterior a un vecino de Sevilla para que le representase en la Chancillería de Granada para demostrar su supuesto origen, pues declaraba que era hijo de una berberisca de Andújar. Su intención era la de residir en la

${ }^{73}$ Interrogatorio, Testificación del barbero morisco Alonso Ruyz, s.f.

74 Interrogatorio, Testificación del corredor de lonja cristianoviejo Lope de Sancúrjal, s.f. El tintorero morisco Salvador Jiménez indicaba que en «las cartas de libertad de los que fueron cautivos se les puso que eran ververiscos y eso lo a visto este testigo en esta ciudad y lo a oido dezir a personas del dicho reyno de Granada que se han hecho gazis».

75 AHPSe, PNS, leg. 172, f. 263r, 16-I-1587. 
ciudad de Granada ${ }^{76}$. Esta modificación en su carta de libertad debía de obedecer al mismo propósito. Fuera cual fuese la extensión de este fraude, siempre contó para su éxito con la aquiescencia de las autoridades judiciales locales, apareciendo en la documentación notarial algunos individuos definidos como «morisco berberisco» ${ }^{77}$. Es por ello que se expidió en 1585 una real provisión por la que se indicaba que todos estos pleitos que sostenían los moriscos para ser cristianos viejos en función de «ser decedientes de tales Christianos viejos como por averse convertido sus passados a nuestra Santa Fe Catholica antes de la Conversion General o venido de Africa a recivirla $\rangle^{78}$ fueran vistos sólo en la Junta de Población y no en las instancias judiciales regionales o locales. Esta provisión aumentó la presión sobre los

\begin{abstract}
moriscos como los verdaderos mudéjares, [quienes] pretendieron denodadamente instrumentalizar mediante el procedimiento judicial, su adscripción a un status social de cristiano viejo. También los gacis, esclavos o cautivos liberados procedentes de África que se habían convertido voluntariamente, estaban afectos a esta norma jurídica y trataron de probar su linaje diferenciado del de morisco natural del reino de Granada ${ }^{79}$
\end{abstract}

Por último, todos los testigos decían conocer a los líderes de la comunidad gazi, Andrés de Barrientos y Pedro de Molina. Barrientos era panadero, natural de la Hoya de Málaga, según algunos testimonios, que corroboraba uno de los moriscos malagueños más importantes en Sevilla, el médico comareño Alonso Gil, quien según el morisco Hernando de Mendoza le había indicado que

en cumplimento del bando que se echo el año de ochenta e zinco se echaron de Granada todos los gazes que avia en ella juntamente con los moriscos e que este

76 AHPSe, PNS, leg. 170, f. 458r, 15-VI-1586, «pues soi berberisco y no morisco de los del rreino de Granada pueda yr y benir y estar y pasar y rresidir en la dicha çiudad de Granada y las demas çiudades villas y lugares del dicho rreino y en donde esta proibido a los moriscos del dicho reino de Granada porque yo no soi comprehendido en la dicha probiçion».

${ }_{77}$ Conocemos el caso de Diego de Benavides, «morisco berberisco» que otorga testamento al haber sido acuchillado por otros moriscos y en el que aparece como acreedor de varios correligionarios, o Luis Martín, que compró a Ana, esclava de Doña Beatriz Dalvo también «morisca berberisca» por 25 ducados en 21-IV-1587, entre otros. AHPSe, PNS, leg. 141, f. 1295, 15-XII-1576, ibid, leg. 172, f. 1418r.

78 Izquierdo, La expulsión de los moriscos del Reino de Granada (pragmáticas, provisiones y órdenes reales), p. 43.

79 Sobre este tema, García Gómez, "La provisión real de 3 de septiembre de 1585: los procesos sobre la condición social de los moriscos de la corona de Castilla”, p. 176. 
testigo a oydo dezir a maese Alonso Gil e a otras personas que el dicho Andres de Barrientos es uno de los gazes que se echaron de la Hoya de Malaga... en el dicho año de ochenta y zinco ${ }^{80}$.

Alonso Gil tenía una ejecutoria de cristiano viejo dada por la Audiencia de Sevilla en 1585 y era uno de los moriscos más relevantes de la comunidad en la ciudad de Sevilla, habiendo sido el traductor para el cabildo de la ciudad de las profecías que aparecieron en el tiempo de la rebelión frustrada de $1580^{81}$, y miembro prominente de su comunidad en el barrio de San Bernardo ${ }^{82}$. Otros testimonios abundan en el hecho de que Barrientos y Molina eran unos recién llegados a la ciudad, puesto que habían sido deportados en 1585, cuando «salieron de la dicha ziudad de Malaga e costa de la mar todos los gasis berveriscos que en ella avia y entre ellos los dichos Andres de Barrientos y Pedro de Molina ${ }^{83}$. Con ello también se incidía en el hecho de que no habían tenido tiempo de ser considerados como vecinos y por tanto su actuación frente a la comunidad morisca ya constituída tenía poca credibilidad $^{84}$.

Pedro de Molina era según un testigo, «muy cabal e que el dicho era esclavo cativo de un vezino de la dicha ciudad de Malaga» y junto a Barrientos «ambos fueron moros y deçendientes de moros berveriscos». Su oficio era mucho más especializado que el de Barrientos, pues era cirujano ${ }^{85}$. Molina coincidió en la ciudad con otros cirujanos berberiscos como el maestre Juan Ximenez, «cirujano berberisco natural de la ciudad de Fes e vecino de la ciudad de Cordoba» quien en 1584 se había concertado con un procurador de causas de la ciudad de Sevilla para curarlo de una úlcera sangrante en una pierna ${ }^{86}$.

${ }^{80}$ Interrogatorio, Testificación del morisco Hernando de Mendoza, especiero vecino de San Isidro, s.f.

${ }^{81}$ Pérez García y Fernández Chaves, Las élites moriscas.

82 AGS, CC, libro de cédulas, 263, f. 13v, 23-X-1585.

${ }^{83}$ Interrogatorio, Testificación del morisco Hernando de Galves, antiguo vecino de Comares, s.f.

${ }^{84}$ Sobre el concepto de vecino, Herzog, Vecinos y extranjeros. Hacerse español en la Edad Moderna.

${ }^{85}$ Interrogatorio, Testificación del morisco Hernando de Galves, antiguo vecino de Comares, s.f. Hernando de Mendoza lo calificaba como «uno que cura enfermos como medico».

${ }^{86}$ AHPSe, PNS, leg. 1592, f. 563r, 7-VIII-1584. El coste de la cura fue de 16 ducados. 
Así pues, junto con el comareño Alonso Gil aparecen dos gazis como profesionales de la medicina, por lo que a la importante masa de esclavos sin formación definida se añaden gazis con perfiles laborales más especializados que nos avisan de una variedad en esta población más acusada de lo que podría suponerse en un principio. Si bien el oficio de Barrientos no era tan complejo, no es menos cierto que algunos de los moriscos de la ciudad se habían especializado en el sector del pan y tenían una cierta importancia económica ${ }^{87}$. Los líderes de los gazis son oriundos de Málaga, y la ausencia de referencias a gazis granadinos nos indica que, más allá de un problema de identificación entre gazis y moriscos, se encuentra otro relativo a pugnas entre la élite granadina afincada en Sevilla, que controla el servicio, y algunos malagueños recién llegados poco dispuestos a cooperar, además de los mudéjares $^{88}$. En la imagen difamatoria que se dibuja en el interrogatorio el morisco Hernando de Mendoza apostillaba:

e que a los gazes que este testigo tiene dicho que conozio en la ziudad de Granada no son de los que este testigo a visto que litigan este pleito porque si lo fueran este testigo los conoçiera por vivir como vivia en la dicha ziudad de Granada a donde vido venian de pazes muncha cantidad de los dichos naturales del dicho reyno de Granada y entre ellos algunos gazes que venian casados con moriscas del dicho reino de Granada y que estos los vido este testigo estando a la sazon en servicio de don Alonso de Venegas que hera la persona que recivia de pazes los moriscos de las Alpujarras ${ }^{89}$.

Hernando de Mendoza era además uno de los más importantes moriscos de la ciudad, que había estado muy próximo a los Venegas aunque esto no le había evitado la expulsión. Se dedicaba a la especiería, como la mayor parte de la élite de los granadinos relacionados con el servicio morisco, siendo el caso del propio comisario Alonso Hernández de Represa, el morisco Diego Anríquez o el poderoso y respetado

${ }^{87}$ Fernández Chaves y Pérez García, En los márgenes de la ciudad de Dios, pp. 225, 265-266.

${ }^{88}$ Este hecho es muy interesante, porque sitúa el conflicto conocido entre los «mudéjares antiguos» de Castilla y los moriscos en latitudes hasta ahora no exploradas. Véase, Gómez Vozmediano, Mudéjares y moriscos en el Campo De Calatrava. Reductos de convivencia, tiempos de intolerancia (Siglos XV-XVII) y Moreno Díaz del Campo, Los moriscos de la Mancha. Sociedad, economía y modos de vida de una minoría en la Castilla moderna, entre otros.

${ }^{89}$ Interrogatorio, Testificación del morisco Hernando de Mendoza, especiero vecino de San Isidro, s.f. 
mercader y especiero Melchor de Berrio, también incluido en la probanza como testigo ${ }^{90}$. Melchor de Berrio y su hermano Lorenzo fueron dos de los grandes impulsores de la negociación del servicio morisco, negociando en la corte y en las comunidades de Toledo y Sevilla entre otras $^{91}$, mientras que el resto de los moriscos aquí reseñados fueron miembros muy importantes de la comunidad hispalense, perteneciendo en algunos casos a la nobleza morisca, como Diego Anríquez.

Dos testigos pusieron de ejemplo de gazi (a veces también llamado berberisco) que abonaba puntualmente el pago del servicio a Diego Sánchez, que residía en la villa de Zafra ${ }^{92}$, y era socio comercial y repartidor del primer servicio en la zona de Badajoz junto a otro morisco granadino afincado en Sevilla, Alonso Hernández Camit, por lo que pese a su condición de berberisco no se podía presumir que fuese a dejar de abonar el servicio que él mismo cobraba ${ }^{93}$. Aunque hasta el momento las fuentes indicaban que Diego Sánchez era un morisco ${ }^{94}$, los testigos de este pleito apuntan a su condición de gazi. Quizá estemos ante un nuevo caso de «transformación» de identidades como hemos visto anteriormente. Sea como fuere, es cierto que la colaboración de berberiscos con moriscos fue frecuente, puesto que los primeros gozaban de una libertad de movimientos física ${ }^{95} \mathrm{y}$ legal mucho mayor, asimilada a los berberiscos. En algunos casos los moriscos apoderaban a berberiscos para que resolvieran sus asuntos en el reino de Granada, como hizo el propio Melchor de Berrio en 1586 con el berberisco Diego Márquez, y sucedió en muchas otras ocasiones ${ }^{96}$.

Por su parte, los moriscos malagueños integrados en el entramado de poder morisco contribuyen con sus testimonios a poner distancia entre ellos y estos gazis. Estos moriscos fueron, Hernando de Galves,

${ }^{90}$ Sobre el perfil de esta élite, cfr. Pérez García y Fernández Chaves, Las élites moriscas.

91 Pérez García y Fernández Chaves, "Los hermanos Berrio".

92 Interrogatorio, Testimonios de Hernando de Mendoza y Alonso de Herrera.

${ }^{93}$ Sobre Sánchez y el Camit, Pérez García y Fernández Chaves, "La gestión de la fiscalidad".

${ }_{94}$ Pérez García y Fernández Chaves, "La gestión de la fiscalidad".

95 Sobre las licencias para mudar de residencia o comerciar véase, de Tapia Rodríguez, "Las redes comerciales de los moriscos de Castilla la vieja: Un vehículo para sus «complicidades»”, pp. 231-243 y García López, Señores, seda y marginados. La comunidad morisca de Pastrana.

96 Pérez García y Fernández Chaves, "Los hermanos Berrio". 
Lorenzo de Comares y de manera indirecta, maese Alonso Gil. Lorenzo de Comares aparece entre los miembros de las juntas de naturales del reino de Granada que se reunieron en Sevilla tanto para acordar el repartimiento de los servicios como para otras actividades de representación ${ }^{97}$.

De esta forma, estos gazis oriundos de Málaga donde representaban una fuerza de trabajo importante y participaban en amplia proporción de la población servil, trataron de organizar a los gazis de Sevilla apoyándose en los mudéjares de la ciudad y en la reivindicación de sus privilegios para escapar del pago del servicio. Por su parte los moriscos recordaban que habían sido incluidos en las últimas sacas de 1585, que habían sido protagonizadas mayoritariamente por moriscos. A punto de comenzar a pagar el segundo servicio morisco en Castilla desde la expulsión de Granada, debía de ser un contratiempo para las élites moriscas en trance de eliminación de sus raíces infamantes el tener que enfrentarse con unos neófitos (en su mayoría) que trataban de tener los mismos privilegios a los que ellos querían acceder sin pagar el servicio que tanto les había costado organizar. Los granadinos lideraban a todo el conjunto social de raigambre islámica en Castilla, fuese cual fuese su origen, y aunque en ocasiones usurpaban la identidad berberisca convirtiéndose en «moriscos berberiscos» si les convenía, preferían deshacer la imagen del gazi asimilándola al esclavo y a la quintaesencia del lumpen, o bien acusando a otros moriscos de querer ampararse en esta condición para no abonar el servicio.

Ignoramos cómo termina el pleito porque la segunda parte no se ha conservado, pero los gazis debieron de avenirse a pagar. De esta forma en 1599 el rico mercader morisco Rafael de Cárdenas atestiguaba junto al también morisco Alonso Vanegas como apoderados del «arca de dos llaves donde ser recoje el dinero que los gazis vecinos desta dicha ciudad y su tierra y partidos hazen al rey nuestro señor» que habían recibido de Pedro de Velázquez «ordinario de la ciudad de Xerez de la Frontera» y de Antonio Duarte, jurado de la misma localidad, 2.890 reales de plata que cupieron a repartir entre Jerez, el Puerto de Santa María y Sanlúcar, correspondientes a la paga de $1599^{98}$. Aún en 1600 Represa registraba ante notario el gasto de 873 reales que había desem-

97 Pérez García y Fernández Chaves, Las élites moriscas.

98 AHPSe, PNS, leg. 4180, f. 1057v, Sevilla, 4-XII-1599. 
bolsado en las «costas e gastos que yo he hecho asi en los pleitos que se tratan contra los gazis en esta ciudad y en la villa de Madrid» y otros gastos, lo que nos hace ver que la oposición al pago no quedó solamente como un asunto local, trascendiendo sus apelaciones hasta la corte $^{99}$.

Esta visibilidad fiscal desaparece sin embargo en la expulsión, pues no se les menciona como tales en los bandos, aunque esto es algo ambiguo pues el bando de expulsión andaluz rezaba:

ordeno y mando, que todos los Christianos nuevos Moriscos, sin exceptar ninguno, que biven y residen en los dichos Reynos de Granada, y Murcia, y Andaluzia, y la dicha villa de Hornachos, assi hombres, como mugeres de qualquier edad que sean, tanto los naturales dellos, como no naturales, que en qualquier manera, o por qualquier causa ayan venido y esten en los dichos Reynos, excepto los que fueren esclavos, salgan dentro de treynta dias primeros siguientes, que se quenten desde el dia de la publicacion de esta mi Cedula, de todos estos mis Reynos y Señorios de España, con sus hijos, y hijas, y criados, y criadas, y familiares de su nacion, assi grandes como pequeños ${ }^{100}$.

Parece que al indicar «naturales y no naturales» y «que en qualquier manera, o por qualquier causa ayan venido y esten en los dichos Reynos» el bando alude directamente a los berberiscos y por supuesto gazis, aunque como es sabido éstos no se incluyeron en la expulsión, pues pronto se incluyeron unas aclaraciones sobre los nuevos convertidos berberiscos o turcos y sus descendientes que los exceptuaban ${ }^{101}$.

Por todo ello podemos concluir siquiera de forma preliminar que el término «gazi» volvió a emplearse en el nuevo ajuste fiscal que se produjo después de 1588 y del que los millones constituyen la muestra más evidente. Esta categoría se invocaba por la administración para marcar la igualdad fiscal de este colectivo con el resto de moriscos y mudéjares antiguos, mientras que los gazis recordaban su origen norteafricano y por tanto su diferenciación con los otros dos colectivos, con lo que se trataba de evitar el pago del servicio de los naturales del

99 AHPSe, PNS, leg. 4182, f. 416v-417r. 26-IV-1600.

${ }^{100}$ Don Ivan de Mendoça Marqves de San German, Gentilhombre de la Camara de su Magestad, de su Real Consejo de la Guerra, y Capitan General del Artilleria de España, Matías Clavijo, Sevilla, 13 de enero de 1610. En Izquierdo, La expulsión de los moriscos, p. 50 . 416

101 Fernández Chaves y Pérez García, En los márgenes de la ciudad de Dios, pp. 415- 
Reino de Granada. En este panorama, y si hacemos caso de las palabras de los moriscos, los gazis no podían escapar a la nueva fiscalidad. Los gazis presentes en Sevilla, a caballo entre un pasado berberisco y una convivencia «fuerte» con los moriscos trataron de esquivar la voracidad de un sistema impositivo que desde el siglo XV discriminaba a los bautizados en aras de un mayor rendimiento fiscal. No en vano todos los interesados en el pago solicitaron para el último servicio que llegó a organizarse en $1602^{102}$ y que comenzaría a pagarse en 1603, que no se les considerase ni llamase en adelante moriscos ni moros, con lo que la minoría trataba de evitar uno de los elementos que refundaban constantemente el origen de la desigualdad de la que eran objeto ${ }^{103}$. El éxito político que los moriscos se apuntaron al incluir en su categoría a los mudéjares antiguos y gazis entendidos en sentido amplio terminó en cuanto se produjo la expulsión quedando exceptuados los berberiscos y turcos. Pero esta inclusión no estuvo exenta de tensiones en el seno de la comunidad neoconversa, hecho que pone en cuestión la monolítica visión que sobre este colectivo ofrecían muchos autores contemporáneos.

En definitiva, la fiscalidad de la monarquía contribuyó a animar la figura de la nación morisca y sus agregados minoritarios como mudéjares antiguos y gazis, cuyo pasado islámico estaba sin duda más desdibujado que el de los recién llegados norteafricanos o turcos, a quienes se les perdonaba su presencia en la península por «venirse a convertir», lo que significaba una vez más que estos grupos continuaban incurriendo en la desigualdad fiscal no tanto por su comportamiento religioso, que algunos apologetas de la expulsión tornarán hereditario ${ }^{104}$, sino por un pacto realizado con la corona e impulsado por ellos mismos, como se ha demostrado ${ }^{105}$. Dentro de este pacto, no pesaba tanto la noción de traidores a la fe como la de traidores al rey por el delito

102 Bravo Caro, "Un impuesto de desterrados", p. 52.

103 Moreno Díaz del Campo, "El último servicio morisco".

104 Véase Perceval, Todos son uno. Arquetipos, xenofobia y racismo. La imagen del morisco en la monarquía española durante los siglos XVI y XVII; Moreno Díaz del Campo, "El espejo del rey. Felipe III los apologistas y la expulsión de los moriscos"; Feros Carrasco, "Retóricas de la expulsión", pp. 67-101.

${ }^{105}$ Vincent, "Los moriscos granadinos"; Moreno Díaz del Campo, "El último servicio morisco"; Pérez García y Fernández Chaves, "Los hermanos Berrio". 
de lesa majestad al haberse rebelado contra Felipe $\mathrm{II}^{106}$. Los gazis fueron incluidos en este pacto fiscal por su permanencia en el reino de Granada, aunque su origen extragranadino pudiera haberles asimilado a los berberiscos que continuaban llegando, lo que nos indica el ascendiente político y la iniciativa que los moriscos tenían sobre el resto de poblaciones (mudéjares antiguos, berberiscos, gazis, etc.), de pasado islámico a finales del siglo XVI en la Monarquía Hispánica.

\section{Bibliografía}

Alonso Acero, Beatriz, Sultanes de Berbería en tierras de cristiandad. Exilio musulmán, conversión y asimilación en la Monarquía Hispánica, siglos XVI y XVII, Barcelona, Bellaterra, 2006.

Arroyal Espigares, Pedro José, Cruces Blanco, Esther y Martín Palma, María Teresa, (coaut.), Galán Sánchez, Ángel (estudio), Cedulario del Reino de Granada (1511-1514), Málaga, Universidad, 2008.

Bravo Caro, Juan Jesús, "Un impuesto de desterrados. El servicio de los naturales del Reino de Granada", en Estudios modernistas sobre el Reino de Granada. Homenaje al Dr. Joaquín Gil Sanjuán, Málaga, Universidad, 2003, pp. 45-82.

Castillo Fernández, Javier, "Las estructuras sociales", en Manuel Barrios Aguilera (ed.), Historia del Reino de Granada. La época morisca y la repoblación, Granada, Universidad, 2000, pp. 179-230, vol. II, Biblioteca Chronica Nova de Estudios Históricos.

Fernández Chaves, Manuel F., "La súplica al rey y la supervivencia de las élites moriscas del reino de Granada después de 1570: El caso de Doña Brianda Venegas", Chronica Nova. Revista de Historia Moderna de la Universidad de Granada (en prensa).

Fernández Chaves, Manuel F. y Pérez García, Rafael M., En los márgenes de la ciudad de Dios. Moriscos en Sevilla, Valencia, Universitat de València-Universidad de Granada-Universidad de Zaragoza, 2009, Biblioteca de Estudios Moriscos, 6 .

Feros Carrasco, Antonio, "Retóricas de la expulsión", en Mercedes García-Arenal y Gerard Wiegers, (eds.), Los moriscos: expulsión y diáspora. Una perspectiva internacional, Valencia, Universitat de València-Universidad de GranadaUniversidad de Zaragoza, 2013, pp. 67-101.

106 Sobre este tema, García López, "Conflictividad y conciencia"; Fernández Chaves, "La súplica al rey y la supervivencia de las élites moriscas del reino de Granada después de 1570: El caso de Doña Brianda Venegas". 
Galán Sánchez, Ángel, "El dinero del rey y la «ley de la comunidad». Pacto político y contrato fiscal en el Reino de Granada tras la conquista", en François Foronda (dir.), Avant le contrat social. Le contrat politique dans l'Occident médiéval XIIIe-XVe siécle, París, Publications de la Sorbonne, 2011, pp. 653-683.

Galán Sánchez, Ángel, "El precio de la fe en la Castilla Bajomedieval: La fiscalidad de los mudéjares", en Hacienda y Fiscalidad. Actas de las VIII Jornadas de Castilla-La Mancha sobre Investigación en archivos, Guadalajara, Junta de Comunidades de Castilla-La Mancha-Asociación de amigos del Archivo Histórico Provincial de Guadalajara, 2009, pp. 187-212.

Galán Sánchez, Ángel, Los mudéjares del Reino de Granada, Granada, Universidad, 1991, Biblioteca Chronica Nova de Estudios Históricos, 13.

Galán Sánchez, Ángel, Una sociedad en transición: los granadinos de mudéjares a moriscos, Granada, Universidad, 2010.

Galán Sánchez, Ángel y Peinado Santaella, Rafael G., "La communauté et le roi: Formes de recouvrement et résistances fiscales à Grenade après la conquête", en Denis Menjot, Albert Riguaudière y Albert Sánchez Martínez (dirs.), L'impôt dans les villes de l'Occident méditerranéen, XIIIe-XVe siècle, París, Comité pour l'histoire économique et financière de la France, 2005, pp. 427450.

Gallego Burín, Antonio y Gámir Sandoval, Alfonso, Los moriscos del Reino de Granada según el sínodo de Guadix de 1554, Granada, Universidad, 1996, Archivum, 61.

García Gómez, María José, "La provisión real de 3 de septiembre de 1585: los procesos sobre la condición social de los moriscos de la corona de Castilla", en La administración de justicia en la historia de España. Actas de las III Jornadas de Castilla la Mancha sobre investigación en archivos, Guadalajara, Asociación de Amigos del Archivo Histórico Provincial de Guadalajara, 1999, pp. 169-191.

García López, Aurelio, “Conflictividad y conciencia. La aplicación de justicia y la minoría morisca en el reino de Castilla”, en Antonio Mestre Sanchís y Enrique Giménez López (coords.), Disidencias y exilios en la España moderna. Actas de la IV Reunión científica de la Asociación Española de Historia Moderna, Alicante, Universidad, 1997, pp. 455-468.

García López, Aurelio, Señores, seda y marginados. La comunidad morisca de Pastrana, Guadalajara, Bornova, 2009.

Gómez García, María del Carmen y Martín Vergara, Juan María, La esclavitud en Málaga entre los siglos XVI y XVII, Málaga, Diputación Provincial, 1993, Biblioteca Popular Malagueña, Edición de Bolsillo, 57.

Gómez Vozmediano, Miguel Fernando, Mudéjares y moriscos en el Campo De Calatrava. Reductos de convivencia, tiempos de intolerancia (Siglos XVXVII), Ciudad Real, Diputación Provincial, 2000. 
Herzog, Tamar, Vecinos y extranjeros. Hacerse español en la Edad Moderna, Madrid, Alianza, 2006.

Izquierdo, Julio, La expulsión de los moriscos del Reino de Granada (pragmáticas, provisiones y órdenes reales), Granada, Azur, 1983.

Jiménez Estrella, Antonio, "Los bienes confiscados a moriscos huidos al Norte de África: datos sobre su cobro y administración en el Reino de Granada”, en Juan Luis Castellano Castellano y Miguel Luis López-Guadalupe Muñoz (eds.), Homenaje a Don Antonio Domínguez Ortiz, Granada, Universidad, 2008, vol. I, Homenajes/Universidad de Granada, pp. 517-545.

Jiménez Estrella, Antonio, Poder ejército y gobierno en el siglo XVI. La capitanía general del Reino de Granada y sus agentes, Granada, Universidad, 2004, Biblioteca de Humanidades Chronica Nova de estudios históricos.

Juan Lovera, Carmen, “Apuntes sobre Alcalá la Real en época de los Austrias”, Boletín del Instituto de Estudios Giennenses, 162, 2 (1996), pp. 963-984.

Ladero Quesada, Miguel Ángel, Los mudéjares de Castilla en tiempos de Isabel I, Valladolid, Instituto Isabel la Católica de Historia Eclesiástica, 1969.

Lewis, B., Pellat, Ch. y Schacht, J., The Encyclopaedia of Islam, Leiden, Brill, 1983, vol. II.

López de Coca Castañer, José Enrique, “Consideraciones sobre la frontera marítima”, en Pedro Segura Artero (coord.), La frontera oriental nazarí como sujeto histórico (ss. XII-XVI), Almería, Instituto de Estudios Almerienses, 1997, pp. 395-408, Actas, 29.

López de Coca Castañer, José Enrique, "Esclavos, alfaqueques y mercaderes en la frontera del mar de Alborán (1490-1516)”, Hispania, 38, 139 (1978), pp. 275-300.

Mármol Carvajal, Luis del, Historia del rebelión y castigo de los moriscos granadinos, Madrid, Imprenta de Sancha, 1798.

Martín Casares, Aurelia, La esclavitud en la Granada del siglo XVI, Granada, Universidad, 2000, Biblioteca Chronica Nova de Estudios Históricos, 64.

Meneses García, Enrique, Correspondencia del Conde de Tendilla, Madrid, Real Academia de la Historia, 1974, t. II, Archivo Documental Español, 31.

Moreno Díaz del Campo, Francisco Javier, “Aproximación al estudio de las fuentes para el estudio de la fiscalidad morisca: el ejemplo de La Mancha", en Hacienda y Fiscalidad. Actas de las VIII Jornadas de Castilla-La Mancha sobre Investigación en archivos, Guadalajara, Junta de Comunidades de Castilla-La Mancha-Asociación de Amigos del Archivo Histórico Provincial de Guadalajara, 2009, pp. 1-16.

Moreno Díaz del Campo, Francisco Javier, “El espejo del rey. Felipe III los apologistas y la expulsión de los moriscos", en Porfirio Sanz Camañes (coord.), La Monarquía Hispánica en tiempos del Quijote, Madrid, Sílex, 2005, pp. 231-246. 
Moreno Díaz del Campo, Francisco Javier, "El último servicio morisco", (en prensa).

Moreno Díaz del Campo, Francisco Javier, Los moriscos de la Mancha. Sociedad, economía y modos de vida de una minoría en la Castilla moderna, Madrid, CSIC, 2009.

Moreno Trujillo, María Amparo, Osorio Pérez, María José y Obra Sierra, Juan María de la (eds.), Escribir y gobernar: el último registro de correspondencia del Conde de Tendilla (1513-1515), Granada, Universidad, 2007.

Nueva Recopilación de las Leyes de Castilla, Madrid, s.e., 1723.

Peinado Santaella, Rafael. G., Los inicios de la resistencia musulmana en el Reino de Granada (1490-1515), Sevilla, Consejería de Cultura de la Junta de Andalucía-Fundación "El Legado Andalusí”, 2011.

Perceval, José María, Todos son uno. Arquetipos, xenofobia y racismo. La imagen del morisco en la monarquía española durante los siglos XVI y XVII, Almería, Instituto de Estudios Almerienses, 1997.

Pérez de Colosía Rodríguez, María Isabel, "Esclavos berberiscos sentenciados en el Auto de Fe de 1618", Baetica, 20 (1998), pp. 357-365.

Pérez García, Rafael M., "Moriscos en Antequera, 1569-1574”, (en prensa).

Pérez García, Rafael M. y Fernández Chaves, Manuel F., "La gestión de la fiscalidad como medio de ascenso social en el seno de la comunidad morisca granadina, 1502-1610", Historia, Instituciones, Documentos, 42 (2015), (en prensa).

Pérez García, Rafael M. y Fernández Chaves, Manuel F., Las élites moriscas entre Granada y el Reino de Sevilla. Rebelión, castigo y supervivencias, Sevilla, Universidad, 2015.

Pérez García, Rafael M. y Fernández Chaves, Manuel F., "Los hermanos Berrio: capital morisco, mediación política y transformaciones comunitarias", Sharq al-Andalus, (en prensa).

Pregmaticas y Provisiones de su Magestad el Rey don Philippe nuestro señor, sobre la lengua y vestidos, y otras cosas que an de hazer los naturales deste Reyno de Granada, Granada, Imprenta de Hugo de Mena, 1567.

Santos Cabota, Rosario, "El mercado de esclavos berberiscos en la Sevilla del siglo XVII", en Actas del II Congreso de Historia de Andalucía. Andalucía Moderna, Córdoba, Consejería de Cultura y de Medio Ambiente, 1995, vol. 1, pp. 599-615.

Szmolka Clares, Javier (estudio), Moreno Trujillo, María Amparo y Osorio Pérez, María José (ed. y transcrip.), Epistolario del Conde de Tendilla (1504-1506), Granada, Universidad, 1996, 2 tomos, Biblioteca Chronica Nova de Estudios Históricos, Serie Fuentes, 45.

Tapia Rodríguez, Serafín de, "Las redes comerciales de los moriscos de Castilla la vieja: Un vehículo para sus «complicidades»", Studia Historica, Historia Moderna, 11 (1993), pp. 231-243. 
Vincent, Bernard, "Les esclaves à Malaga en 1581”, Estudios de Historia Social, 36-38 (1986), pp. 423-431.

Vincent, Bernard, "Los moriscos granadinos y la monarquía (1570-1609)", en José Ignacio Fortea y Juan Eloy Gelabert (eds.), Ciudades en conflicto (siglos XVI-XVIII), Valladolid, Junta de Castilla y León, 2008, pp. 163-179.

Vincent, Bernard, "Retour sur les monfíes grenadins", en Augustin Redondo (ed.), Le bandit et son image au Siècle d'Or, Madrid, Casa de Velázquez-Publications de la Sorbonne, 1991, pp. 31-37.

Recibido: 01/06/2013

Aceptado: 16/01/2014 